\title{
A Simple Probabilistic Model for Corrosion Evaluation of a Ship's Hull
}

\author{
by Gernot Pirker*, Student Member Yukio Fujimoto**, Member \\ and Samudro*
}

\begin{abstract}
Summary
A probabilistic model for the evaluation of the corrosion degradation of ship hull members is presented. Emphasis is put to obtain a simple relationship between corrosion depth and service time based on the actual data collected from plate thickness measurements. The corrosion phenomenon is assumed to be the result of two sequential processes: generation of pitting points and progress behaviour of pitting points after their generation. Both processes are treated by the probabilistic method. The proposed model is applied to the collected data of plate thickness measurements of Caraka Jaya ships, and the corrosion behaviour of the ship hull members is evaluated. In the second part of the paper, the effect of corrosion on the longitudinal strength degradation of Caraka Jaya ships is discussed.
\end{abstract}

\section{Introduction}

Corrosion is supposed to be the most dominant factor affecting the physical life of ships and offshore structures. An estimate of corrosion rates and a permissible corrosion level are used in the design of ship hull members. As corrosion is the consequence of extremely complex phenomena governed by many factors, corrosion rates and permissible corrosion levels should be determined based on field data obtained by past inspection records.

An annual corrosion rate obtained by dividing the thickness diminution of an aged member by the ship's age at a given time has conventionally been used as the basic criteria due to the ease of assessing and handling. This procedure, however, cannot distinguish between the time during which corrosion is generated and the one of corrosion progress behaviour. A more rational method using a probabilistic model should be established based on the empirical data.

Yamamoto et al. ${ }^{1)}$ proposed a sophisticated probabilistic model of corrosion degradation for ship hull members. In this model, corrosion is as-

* Graduate School of Engineering, Hiroshima University

** Faculty of Engineering, Hiroshima University

Received 7 th July 2000

Read at the Autumn meeting 16, 17 th Nov. 2000 sumed as the result of three sequential processes: degradation of paint coating, generation of pitting points, and progress of pitting points. The unknown parameters used in the model are determined numerically based on the existing data of plate thickness measurements. The maximum likelihood method and the parametric evaluation method are applied to estimate the parameters.

Yamamoto's model yields very accurate results. However, usage of the model is not easy for engineers who are not familiar with reliability analysis. So, in this paper, emphasis is put to develop a simple corrosion model which can be used easily by engineers without loosing the probabilistic nature of corrosion degradation.

In the first part of the paper, a simple model for the corrosion degradation of ship hull members is developed and the applicability of the model is assessed with data from plate thickness measurements of Caraka Jaya ships ${ }^{3)}$. The Caraka Jaya project is one of the biggest series-ship projects in Indonesia.

In the second part of the paper, the deterioration of longitudinal strength of Caraka Jaya ships due to corrosion damage is investigated.

\section{Corrosion Progress Model}

Corrosion of ship hull members is classified into the following three processes by Yamamoto et al. ${ }^{1)}$ :

1. Time of paint coating degradation as the period before active pitting points are generated. 
2. Transition time from active pitting points to progressive pitting points.

3. Progress behaviour of pitting points after their generation.

Yamamoto et al. introduced appropriate probabilistic models for each process. In this paper, however, the first two processes are treated as a single process for the sake of simplicity. The outline of the proposed model is as follows.

The corrosion time $T$ consists of time $T_{0}$ and time $T_{R}$, where $T_{0}$ is the period until the progressive pitting points are generated and $T_{R}$ is the time elapsed for the progress of pitting points. Measurable diminution of plate thickness occurs in the latter period.

$$
T=T_{0}+T_{R}
$$

It is assumed that $T_{0}$ is a random variable following a Weibull distribution.

$$
f_{T_{0}}(t)=\frac{\alpha}{\beta} \cdot\left(\frac{t}{\beta}\right)^{\alpha-1} \cdot \exp \left\{-\left(\frac{t}{\beta}\right)^{\alpha}\right\}
$$

where $\alpha$ and $\beta$ are parameters governed by the protecting paint condition, corrosion environment, etc.

The probability that progressive corrosion has not occurred at the time $T$, denoted by $P_{0}$, can be expressed by the following equation.

$$
P_{0}=\int_{T}^{\infty} f_{T_{0}}(t) \mathrm{d} t=\exp \left\{-\left(\frac{T}{\beta}\right)^{\alpha}\right\}
$$

On the other hand, the probability that measurable corrosion has occurred at time $T$ is given by $\left(1-P_{0}\right)$.

Progress behaviour of pitting points after their generation occurs by both the increase of pitting points in number and their growth in depth and surface directions. By the generation and growth of a lot of pitting points, corrosion unevenness on the plate surface is gradually decreased and approaches to an uniform corrosion condition ${ }^{4)}$. The corrosion depth $Z$ in such condition is thought to be a random variable. In this study, $Z$ is assumed as a random variable following a Weibull distribution.

$$
g_{Z}(z)=\frac{c}{u} \cdot\left(\frac{z}{u}\right)^{c-1} \cdot \exp \left\{-\left(\frac{z}{u}\right)^{c}\right\}
$$

In the above equation, $c$ and $u$ are the parameters governing the characteristics of corrosion depth. In this study, shape parameter $c$ is assumed as constant, while scale parameter $u$ is assumed as a function of $T_{R}$.
From the previous experiments ${ }^{1), 6)}$, it is known that the corrosion depth $Z$ can be expressed as an increasing function with respect to time $T_{R}$. Therefore, the following equation is assumed for the parameter $u$.

$$
u=a \cdot\left(T_{R}\right)^{b}
$$

Coefficient $a$ and exponent $b$ are also parameters related to the corrosion characteristics. The above corrosion process is schematically shown in Fig. 1.

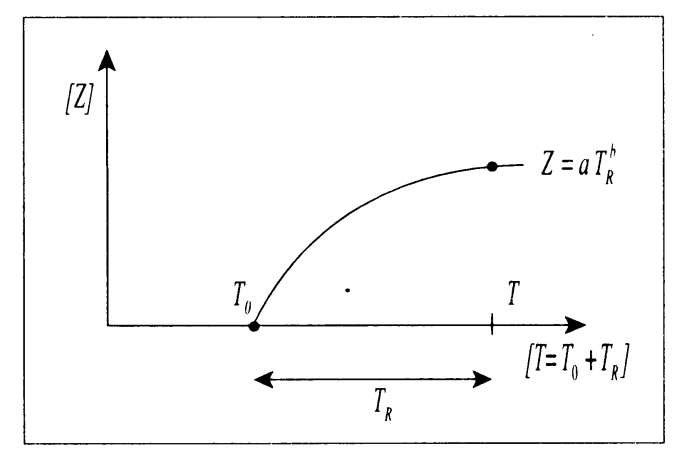

Fig. 1 Corrosion process

From the Eqs. (1) and (2), $T_{R}$ becomes a random variable. The expectation of $T_{R}$ can be given by the following equation.

$$
E\left[T_{R}\right]=\frac{1}{1-P_{0}} \int_{0}^{T}(T-t) f_{T_{0}}(t) \mathrm{d} t
$$

In this study, however, $T_{R}$ is approximated as follows by the use of the medium value of $T_{0}$ for the sake of simplicity.

$$
T_{R}=T-\operatorname{Med}\left(T_{0}\right)
$$

The medium value of $T_{0}$ is written as

$$
\begin{aligned}
\int_{0}^{\operatorname{Med}\left(T_{0}\right)} & f_{T_{0}}(t) \mathrm{d} t \\
= & 1-\exp \left\{-\left(\frac{\operatorname{Med}\left(T_{0}\right)}{\beta}\right)^{\alpha}\right\} \\
= & \frac{1-P_{0}}{2}
\end{aligned}
$$

Solving the above equation with respect to $\operatorname{Med}\left(T_{0}\right)$ yields

$$
\operatorname{Med}\left(T_{0}\right)=\beta \cdot\left\{\ln \frac{2}{1+P_{0}}\right\}^{\frac{1}{\alpha}}
$$

As a result, $T_{R}$ is written as,

$$
T_{R}=T-\beta \cdot\left\{\ln \frac{2}{1+P_{0}}\right\}^{\frac{1}{\alpha}}
$$


Based on the above model, the probability density function of corrosion depth $Z$ at time $T$ is expressed as follows.

$$
f_{Z}(z)=P_{0} \cdot \delta(T)+\left\{1-P_{0}\right\} \cdot g_{Z}(z)
$$

in which $\delta(T)$ is Dirac's delta function. The density function is schematically drawn in Fig. 2.

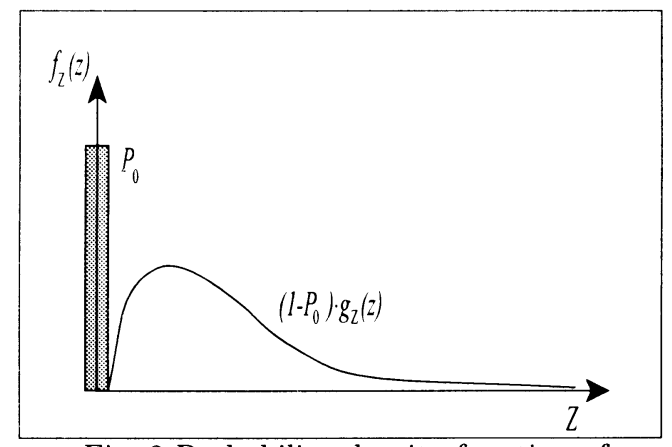

Fig. 2 Probability density function of corrosion depth

The cumulative probability of corrosion depth, denoted by $P(Z)$, is expressed by the following equation

$$
\begin{aligned}
P(Z) & =\int_{0}^{Z} f_{Z}(z) \mathrm{d} z \\
& =P_{0}+\left\{1-P_{0}\right\} \cdot \int_{0}^{Z} g_{Z}(z) \mathrm{d} z \\
& =P_{0}+\left\{1-P_{0}\right\} \cdot\left[1-\exp \left\{-\left(\frac{Z}{u}\right)^{c}\right\}\right]
\end{aligned}
$$

In the above, $u$ is given as follows from the Eqs. (5) and (10).

$$
u=a \cdot\left\{T-\beta \cdot\left(\ln \frac{2}{1+P_{0}}\right)^{1 / \alpha}\right\}^{b}
$$

Substituting the above equation into Eq. (12) and solving the last equation with respect to $z$, we obtain

$$
\begin{aligned}
Z=a & \cdot\left\{T-\beta \cdot\left(\ln \frac{2}{1+P_{0}}\right)^{1 / \alpha}\right\}^{b} \\
& \cdot\left\{\ln \frac{1-P_{0}}{1-P(Z)}\right\}^{1 / c}
\end{aligned}
$$

$P(Z)$ : Cumulative probability of Corrosion depth $Z$.

$P_{0}$ : Probability that progressive corrosion has not occured at time $T$.

$\alpha, \beta, a, b, c: \quad$ unknown parameters

The above equation gives a closed form relationship between corrosion depth $Z$ and time $T$. In order to calculate the corrosion depth $Z$, five parameters ' $\alpha, \beta, a, b$ and $c$ ' must be determined beforehand from empirical data. The Maximum Likelihood Method will be applied for this purpose. When these parameters have been determined, $Z$ can be directly calculated by substituting any $T$ and any $P(Z)$ into Eq. (14).

\section{Maximum Likelihood Method}

\subsection{Estimation of parameters $\alpha$ and $\beta$}

$P_{0}$ and $\left(1-P_{0}\right)$ are the probabilities that measurable corrosion has not occurred and has already occurred at time $T$, respectively. When we carry out plate thickness measurements for $M$ members of the structure at time $T$, and if measurable corrosion is not observed in $M_{1}$ members and measurable corrosion is observed in the other $M_{2}$ members, then the likelihood function of this event can be expressed by the following equation.

$$
L=P_{0}^{M_{1}} \cdot\left(1-P_{0}\right)^{M_{2}}
$$

in which $M_{1}+M_{2}=M$. The log-likelihood of the above equation is

$$
\log L=M_{1} \cdot \log P_{0}+M_{2} \cdot \log \left(1-P_{0}\right)
$$

If plate thickness measurements are carried out at time $T_{1}, T_{2}, T_{3}, \ldots, T_{i}, \ldots, T_{N}$ during the service, the log-likelihood of the whole event is given as follows.

$$
\begin{aligned}
& \log L \\
& =\sum_{i=0}^{N}\left\{M_{1 i} \cdot \log P_{0 i}+M_{2 i} \cdot \log \left(1-P_{0 i}\right)\right\}
\end{aligned}
$$

The parameters $\alpha$ and $\beta$ used in $P_{0}$ can be determined so that the $\log L$ of the equation (17) takes the maximum value for the collected corrosion data $\left(M_{1 i}, M_{2 i}\right), i=1,2,3, \ldots N$.

From the empirical data of coating degradation, it is shown that there is a correlation between mean degrees of degradation of paint coating and their dispersions. In this study, the same coefficient of variation is used for the probability density function of $T_{0}$.

$$
\begin{aligned}
C . O . V . & =\frac{\sqrt{V\left[T_{0}\right]}}{E\left[T_{0}\right]} \\
& =\frac{\sqrt{\Gamma\left(1+\frac{2}{\alpha}\right)-\Gamma^{2}\left(1+\frac{1}{\alpha}\right)}}{\Gamma\left(1+\frac{1}{\alpha}\right)} \\
& =0.4
\end{aligned}
$$


in which $\Gamma(\bullet)$ is the Gamma function. Solving the above equation, we obtain $\alpha=2.70$. For the numerical calculations shown in Chapter 4 , a constant value $\alpha=2.70$ is used and only the value of $\beta$ is determined by the maximum likelihood method.

\subsection{Estimation of parameters $a, b$ and $c$}

For the estimation of $a, b$ and $c$, we will also use the above mentioned maximum likelihood method. The difference here is that there exist three unknown parameters instead of two parameters. In order to reduce the time of calculations, the parameter $b$ is fixed to the four values: $b_{1}=1 / 3$, $b_{2}=1 / 2, b_{3}=2 / 3$ and $b_{4}=1$. The optimal value for $b$ will be selected among these four values.

The parameters $a, b$ and $c$ were introduced in the probability density function of corrosion depth $g_{Z}(z)$ of Eq. (4). Let $m_{i j}$ be the number of members with corrosion depth of the $j$-th state $Z_{j}$ at the $i$-th measurement time $T_{i}$. Although $Z$ is a continuous function, it is usually classified into small intervals and expressed by their discrete representative values $Z_{j}(j=1,2,3, k)$. Of course, the following relationship holds in such classification.

$$
\sum_{j=1}^{k} m_{i j}=M_{2 i}, \quad M_{1 i}+M_{2 i}=M_{i}
$$

When plate thickness measurements are carried out at times $T_{1}, T_{2}, \ldots, T_{\imath}, \ldots, T_{N}$ and the number of members which belong to the $j$-th corrosion state, $m_{i j}(j=1,2,3, \ldots, k)$, are obtained at each $T_{i}$, then the likelihood function for all the measured data can be expressed as

$$
L=\prod_{i=1}^{N} \prod_{j=1}^{k}\left[g_{Z}\left(z_{j} \mid u_{i}\right)^{m_{i j}}\right]
$$

Taking the logarithm of the above equation, the log-likelihood function is obtained as follows.

$$
\begin{aligned}
\log L= & \sum_{i=1}^{N} \sum_{j=2}^{M} m_{i j} \cdot\left\{\operatorname { l o g } \left[\left(1-P_{0 i}\right) \frac{c}{u_{i}}\right.\right. \\
& \left.\left.\cdot\left(\frac{z_{j}}{u_{i}}\right)^{c-1} \cdot \exp \left\{-\left(\frac{z_{j}}{u_{i}}\right)^{c}\right\}\right]\right\}
\end{aligned}
$$

where

$$
u_{i}=a \cdot\left\{T_{i}-\beta \cdot\left(\ln \frac{2}{1+P_{0_{i}}}\right)^{\frac{1}{\alpha}}\right\}^{b}
$$

The parameters $a, b$ and $c$ are estimated so that $\log L$ of Eq. (21) takes its maximum value.

In the actual estimation of the parameters, $\alpha$ and $\beta$ are obtained first. Then, the parameters $a, b$ and $c$ are estimated.

Table 1 Corrosion data of Caraka Jaya ships

\begin{tabular}{|c||c|c|c|c|c|c|c|c|c|c|c|c|c|}
\hline \multicolumn{1}{|c|}{ Main Deck } & \multicolumn{10}{c|}{ Depth of corrosion (mm) } \\
\hline Year & 0 & $0-0.5$ & $0.5-1$ & $1-1.5$ & $1.5-2$ & $2-2.5$ & $2.5-3$ & $3-3.5$ & $3.5-4$ & $4-4.5$ & $4.5-5$ & $5<$ & Total \\
\hline \hline $3-3.5$ & 8 & 8 & 7 & 3 & 3 & 0 & 2 & 0 & 0 & 0 & 0 & 0 & 31 \\
$4-4.5$ & 1 & 10 & 6 & 1 & 0 & 0 & 0 & 0 & 0 & 0 & 0 & 0 & 18 \\
$4.5-5$ & 1 & 0 & 3 & 7 & 13 & 12 & 7 & 2 & 0 & 0 & 0 & 0 & 45 \\
$5-5.5$ & 14 & 27 & 8 & 15 & 4 & 5 & 3 & 0 & 0 & 0 & 0 & 0 & 76 \\
$5.5-6$ & 3 & 55 & 1 & 1 & 0 & 0 & 0 & 0 & 0 & 0 & 0 & 0 & 60 \\
$7-7.5$ & 0 & 0 & 0 & 0 & 0 & 0 & 2 & 4 & 0 & 0 & 0 & 0 & 6 \\
$8-8.5$ & 24 & 14 & 1 & 0 & 0 & 0 & 0 & 0 & 0 & 0 & 0 & 0 & 39 \\
$8.5-9$ & 4 & 0 & 8 & 3 & 17 & 8 & 2 & 2 & 5 & 0 & 0 & 0 & 49 \\
$9.5-10$ & 0 & 22 & 7 & 2 & 0 & 0 & 1 & 0 & 0 & 0 & 0 & 0 & 32 \\
\hline \hline Total & 55 & 136 & 41 & 32 & 37 & 25 & 17 & 8 & 5 & 0 & 0 & 0 & 356 \\
\hline
\end{tabular}

\begin{tabular}{|c||c|c|c|c|c|c|c|c|c|c|c|c|c|}
\hline \multicolumn{1}{|c|}{ Tanktop } & \multicolumn{10}{c|}{ Depth of corrosion $(\mathrm{mm})$} \\
\hline \multicolumn{1}{|c||}{ Year } & 0 & $0-0.5$ & $0.5-1$ & $1-1.5$ & $1.5-2$ & $2-2.5$ & $2.5-3$ & $3-3.5$ & $3.5-4$ & $4-4.5$ & $4.5-5$ & $5<$ & Total \\
\hline \hline $1-1.5$ & 0 & 22 & 29 & 34 & 47 & 16 & 2 & 0 & 0 & 0 & 0 & 0 & 150 \\
$3-3.5$ & 22 & 78 & 7 & 0 & 0 & 0 & 0 & 0 & 0 & 0 & 0 & 0 & 107 \\
$4-4.5$ & 0 & 55 & 3 & 0 & 0 & 0 & 0 & 0 & 0 & 0 & 0 & 0 & 58 \\
$4.5-5$ & 1 & 15 & 30 & 7 & 0 & 2 & 0 & 0 & 0 & 0 & 0 & 0 & 55 \\
$5-5.5$ & 20 & 1 & 1 & 7 & 4 & 2 & 2 & 0 & 0 & 0 & 0 & 0 & 37 \\
$5.5-6$ & 39 & 129 & 9 & 1 & 0 & 0 & 0 & 0 & 0 & 0 & 0 & 0 & 178 \\
$7-7.5$ & 0 & 4 & 8 & 6 & 10 & 1 & 0 & 0 & 0 & 0 & 0 & 0 & 29 \\
$8.5-9$ & 0 & 0 & 11 & 37 & 34 & 6 & 0 & 0 & 0 & 0 & 0 & 0 & 88 \\
$9.5-10$ & 0 & 48 & 26 & 2 & 0 & 0 & 0 & 0 & 0 & 0 & 0 & 0 & 76 \\
\hline \hline Total & 82 & 352 & 124 & 94 & 95 & 27 & 4 & 0 & 0 & 0 & 0 & 0 & 778 \\
\hline
\end{tabular}




\begin{tabular}{|c|c|c|c|c|c|c|c|c|c|c|c|c|c|}
\hline \multicolumn{14}{|c|}{ Bulk Head - Cargo Hold } \\
\hline \multirow[b]{2}{*}{ Year } & \multicolumn{12}{|c|}{ Depth of corrosion $(\mathrm{mm})$} & \multirow[b]{2}{*}{ Total } \\
\hline & 0 & $0-0.5$ & $0.5-1$ & $1-1.5$ & $1.5-2$ & $2-2.5$ & $2.5-3$ & $3-3.5$ & $3.5-4$ & $4-4.5$ & $4.5-5$ & $5<$ & \\
\hline $3-3.5$ & 12 & 5 & 1 & $\overline{0}$ & $\overline{2}$ & $\overline{0}$ & 0 & $\overline{0}$ & 0 & $\overline{0}$ & $\overline{0}$ & $\overline{0}$ & 20 \\
\hline $4-4.5$ & 1 & 34 & 7 & 1 & 0 & 0 & 0 & 0 & 0 & 0 & 0 & 0 & 43 \\
\hline $5-5.5$ & 3 & 1 & 5 & 0 & 0 & 0 & 0 & 0 & 0 & 0 & 0 & 0 & 9 \\
\hline $8-8.5$ & 52 & 18 & 0 & 0 & 0 & 0 & 0 & 0 & 0 & 0 & 0 & 0 & 70 \\
\hline $9.5-10$ & 20 & 16 & 16 & 4 & 1 & 0 & 0 & 0 & 0 & 0 & 0 & 0 & 57 \\
\hline Total & 88 & $\overline{74}$ & 29 & 5 & 3 & $\overline{0}$ & $\overline{0}$ & $\overline{0}$ & 0 & $\overline{0}$ & 0 & $\overline{0} 0$ & $\overline{199}$ \\
\hline
\end{tabular}

\begin{tabular}{|c|c|c|c|c|c|c|c|c|c|c|c|c|c|}
\hline \multicolumn{14}{|c|}{ Bottom Plate } \\
\hline \multirow[b]{2}{*}{ Year } & \multicolumn{12}{|c|}{ Depth of corrosion $(\mathrm{mm})$} & \multirow[b]{2}{*}{ Total } \\
\hline & 0 & $0-0.5$ & $0.5-1$ & $1-1.5$ & $1.5-2$ & $2-2.5$ & $2.5-3$ & $3-3.5$ & $3.5-4$ & $4-4.5$ & $4.5-5$ & $5<$ & \\
\hline $0-0.5$ & 0 & 0 & 0 & $\overline{0}$ & $\overline{0}$ & $\overline{1}$ & $\overline{5}$ & $\overline{11}$ & $\overline{6}$ & $\overline{1} 1$ & $\overline{0}$ & $\overline{2}$ & $\overline{26}$ \\
\hline $0.5-1$ & 61 & 1 & 2 & 0 & 0 & 0 & 0 & 2 & 0 & 0 & 0 & 0 & 66 \\
\hline $2-2.5$ & 34 & 33 & 7 & 15 & 7 & 1 & 0 & 1 & 0 & 0 & 0 & 0 & 98 \\
\hline $3-3.5$ & 43 & 57 & 12 & 2 & 7 & 5 & 0 & 1 & 0 & 0 & 0 & 1 & 128 \\
\hline $4-4.5$ & 0 & 18 & 4 & 3 & 1 & 2 & 2 & 0 & 0 & 0 & 0 & 0 & 30 \\
\hline $4.5-5$ & 76 & 36 & 18 & 13 & 7 & 2 & 0 & 1 & 1 & 0 & 0 & 5 & 159 \\
\hline $5-5.5$ & 3 & 20 & 26 & 5 & 4 & 0 & 0 & 0 & 2 & 0 & 0 & 0 & 60 \\
\hline $5.5-6$ & 26 & 68 & 13 & 7 & 0 & 0 & 3 & 0 & 0 & 0 & 0 & 2 & 119 \\
\hline $7-7.5$ & 58 & 4 & 6 & 16 & 3 & 3 & 2 & 1 & 0 & 0 & 0 & 2 & 95 \\
\hline $7.5-8$ & 9 & 47 & 4 & 2 & 0 & 0 & 0 & 0 & 0 & 0 & 0 & 1 & 63 \\
\hline $8.5-9$ & 6 & 30 & 16 & 6 & 0 & 1 & 0 & 0 & 0 & 0 & 0 & 0 & 59 \\
\hline $9.5-10$ & 1 & 29 & 7 & 2 & 0 & 3 & 4 & 5 & 0 & 0 & 0 & 1 & 52 \\
\hline Total & 317 & 343 & 115 & 71 & 29 & 18 & 16 & 22 & $\overline{99}$ & $\overline{1}$ & $\overline{0}$ & 16 & 957 \\
\hline
\end{tabular}

\begin{tabular}{|c|c|c|c|c|c|c|c|c|c|c|c|c|c|}
\hline \multicolumn{14}{|c|}{ Bilge Plate } \\
\hline \multirow[b]{2}{*}{ Year } & \multicolumn{12}{|c|}{ Depth of corrosion $(\mathrm{mm})$} & \multirow[b]{2}{*}{ Total } \\
\hline & 0 & $0-0.5$ & $0.5-1$ & $1-1.5$ & $1.5-2$ & $2-2.5$ & $2.5-3$ & $3-3.5$ & $3.5-4$ & $4-4.5$ & $4.5-5$ & $5<$ & \\
\hline $0-0.5$ & $\overline{0}$ & 0 & $\overline{0}$ & 1 & $\overline{0}$ & $\overline{1}$ & 1 & $\overline{2}$ & $\overline{11}$ & $\overline{0}$ & $\overline{0}$ & $\overline{0}$ & $\overline{6} 6$ \\
\hline $0.5-1$ & 58 & 1 & 0 & 0 & 2 & 0 & 1 & 3 & 0 & 0 & 0 & 0 & 65 \\
\hline $2-2.5$ & 14 & 27 & 3 & 3 & 1 & 0 & 2 & 14 & 0 & 0 & 0 & 0 & 64 \\
\hline $3-3.5$ & 33 & 32 & 12 & 3 & 3 & 3 & 4 & 1 & 0 & 0 & 0 & 0 & 91 \\
\hline $4-4.5$ & 3 & 24 & 4 & 2 & 0 & 1 & 0 & 0 & 0 & 0 & 0 & 0 & 34 \\
\hline 4.5-5 & 62 & 42 & 11 & 9 & 3 & 4 & 1 & 1 & 0 & 1 & 0 & 0 & 134 \\
\hline $5-5.5$ & 3 & 18 & 26 & 5 & 1 & 0 & 0 & 0 & 0 & 0 & 0 & 0 & 53 \\
\hline $5.5-6$ & 6 & 51 & 9 & 0 & 1 & 0 & 4 & 0 & 0 & 0 & 0 & 0 & 71 \\
\hline $7-7.5$ & 29 & 3 & 1 & 4 & 2 & 0 & 1 & 0 & 0 & 0 & 0 & 0 & 40 \\
\hline 7.5-8 & 9 & 54 & 2 & 0 & 0 & 0 & 0 & 0 & 0 & 0 & 0 & 0 & 65 \\
\hline $8.5-9$ & 7 & 40 & 13 & 0 & 0 & 0 & 0 & 0 & 0 & 0 & 0 & 0 & 60 \\
\hline $9.5-10$ & 5 & 30 & 12 & 1 & 0 & 0 & 0 & 0 & 0 & 0 & 0 & 0 & 48 \\
\hline Total & 229 & 322 & 93 & 28 & 13 & 9 & 14 & 21 & 1 & 1 & 0 & 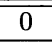 & 731 \\
\hline
\end{tabular}

\begin{tabular}{|c||c|c|c|c|c|c|c|c|c|c|c|c|c|}
\hline \multicolumn{1}{|c|}{ Side Plate } \\
\hline \multicolumn{1}{|c|}{ Year } & 0 & $0-0.5$ & $0.5-1$ & $1-1.5$ & $1.5-2$ & $2-2.5$ & $2.5-3$ & $3-3.5$ & $3.5-4$ & $4-4.5$ & $4.5-5$ & $5<$ & Total \\
\hline \hline $0.5-1$ & 65 & 2 & 0 & 0 & 2 & 0 & 3 & 0 & 1 & 0 & 0 & 0 & 73 \\
$2-2.5$ & 0 & 0 & 0 & 0 & 0 & 0 & 3 & 0 & 0 & 0 & 0 & 0 & 3 \\
$3-3.5$ & 25 & 6 & 5 & 3 & 3 & 1 & 6 & 0 & 0 & 0 & 0 & 0 & 49 \\
$4-4.5$ & 4 & 30 & 7 & 1 & 0 & 0 & 0 & 0 & 0 & 0 & 0 & 0 & 42 \\
$4.5-5$ & 26 & 47 & 13 & 11 & 0 & 0 & 0 & 0 & 0 & 0 & 0 & 0 & 97 \\
$5-5.5$ & 17 & 3 & 7 & 2 & 0 & 0 & 1 & 0 & 0 & 0 & 0 & 0 & 30 \\
$5.5-6$ & 0 & 0 & 1 & 0 & 0 & 0 & 0 & 0 & 0 & 0 & 0 & 0 & 1 \\
$7.5-8$ & 1 & 42 & 0 & 0 & 0 & 0 & 0 & 0 & 0 & 0 & 0 & 0 & 43 \\
$8.5-9$ & 1 & 17 & 4 & 2 & 0 & 0 & 0 & 0 & 0 & 0 & 0 & 0 & 24 \\
$9.5-10$ & 2 & 34 & 9 & 2 & 0 & 0 & 0 & 0 & 0 & 0 & 0 & 0 & 47 \\
\hline \hline Total & 141 & 181 & 46 & 21 & 5 & 1 & 13 & 0 & 1 & 0 & 0 & 0 & 409 \\
\hline
\end{tabular}




\begin{tabular}{|c||c|c|c|c|c|c|c|c|c|c|c|c|c|}
\hline \multicolumn{1}{|c|}{ Second Deck } \\
\hline \multicolumn{1}{|c|}{ Year } & 0 & $0-0.5$ & $0.5-1$ & $1-1.5$ & $1.5-2$ & $2-2.5$ & $2.5-3$ & $3-3.5$ & $3.5-4$ & $4-4.5$ & $4.5-5$ & $5<$ & Total \\
\hline \hline $4-4.5$ & 0 & 18 & 2 & 2 & 0 & 1 & 0 & 0 & 0 & 0 & 0 & 0 & 23 \\
$8-8.5$ & 39 & 9 & 0 & 0 & 0 & 0 & 0 & 0 & 0 & 0 & 0 & 0 & 48 \\
$8.5-9$ & 5 & 2 & 46 & 3 & 4 & 0 & 1 & 0 & 0 & 0 & 0 & 0 & 61 \\
\hline \hline Total| & 44 & 29 & 48 & 5 & 4 & 1 & 1 & 0 & 0 & 0 & 0 & 0 & 132 \\
\hline
\end{tabular}

\section{Application of the Proposed Model to the Structure}

\subsection{Corrosion data of Caraka Jaya ships}

The proposed model was applied to the corrosion data collected from seventeen Caraka Jaya ships. The ships were general cargo and semi container ships of 3,000 DWT and 3,650 DWT built in first and second phases of Caraka Jaya project. Corrosion survey was carried out by the Assessment and Application of Technology (BPPT-Indonesia) in 1998. The survey includes plate thickness measurements and data collection of previous inspection records.

Collected data were from the points of main deck, tank top, bulkhead (cargo hold), bottom plate, bilge plate and side plate. Totally, 3,430 points of data were collected. The annual corrosion rate of each location was investigated in reference $^{2)}$. After that, additional thickness measurements were carried out for the second deck members. Table 1 shows the measured data, in which the relationship between corrosion depth $Z$ and measurement time $T$ is summarized.

\subsection{Evaluation of corrosion diminution of Caraka Jaya ships}

Table 2 shows the parameters estimated by the maximum likelihood method. Parameter $\alpha$ was fixed to 2.70 and the optimal $\beta$ was searched in the range between 1 year and 15 years by the use of the Eq. (17).

\section{Caraka Jaya (Main Deck)}

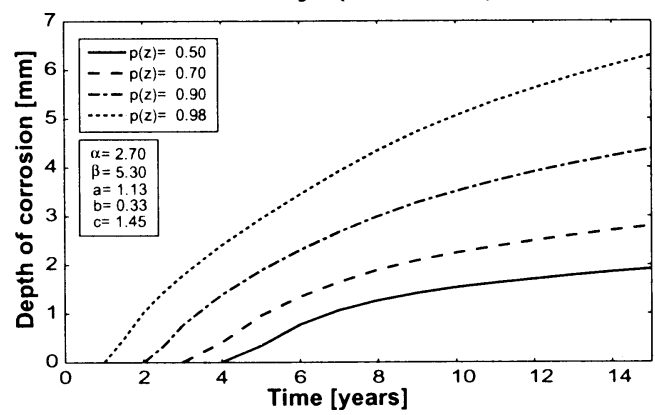

(a) On main deck
Table 2: Parameters for Caraka Jaya ships

\begin{tabular}{|l||r|r|r|r|r|}
\hline Member & $\alpha$ & $\beta$ & $a$ & $b$ & $c$ \\
\hline \hline Main Deck & 2.7 & 5.3 & 1.1 & 0.3 & 1.4 \\
Tank Top & 2.7 & 3.6 & 0.6 & 0.5 & 2.0 \\
Bulk Hd. & 2.7 & 8.7 & 0.7 & 0.3 & 2.0 \\
Bottom Plt. & 2.7 & 5.3 & 0.9 & 0.3 & 1.3 \\
Bilge Plt. & 2.7 & 5.2 & 0.6 & 0.3 & 1.4 \\
Side Plt. & 2.7 & 4.7 & 0.7 & 0.3 & 1.4 \\
2nd Deck & 2.7 & 7.9 & 0.8 & 0.3 & 2.2 \\
\hline
\end{tabular}

The search ranges of the parameters $a$ and $c$ were set from 0.01 to 1.5 and from 0.1 to 5 , respectively. Parameter $b$ was selected among $b_{1}=1 / 3$, $b_{2}=1 / 2, b_{3}=2 / 3$ and $b_{4}=1$ as explained in section 3.2. The optimal $a, b$ and $c$ were determined by the use of Eq. (21).

The estimated values of the parameters were used for the corrosion evaluation. Equation (14) is used for this purpose. Figure 3 shows the result of the evaluations for main deck, tank top, bulkhead (cargo hold), bottom plate, bilge plate, side plate and second deck. The corrosion depth $Z$ that corresponds to the cumulative probabilities of $P(Z)=50,70,90$ and 98 percent were drawn as a function of the ship's age.

In Fig. 3, the relationship between corrosion depth $Z$ and ship's age $T$ (years) is shown for respective $P(Z)$. This calculation is quite simple because $Z$ can be directly calculated by substituting $Z$ and $P(Z)$ into Eq. (14)

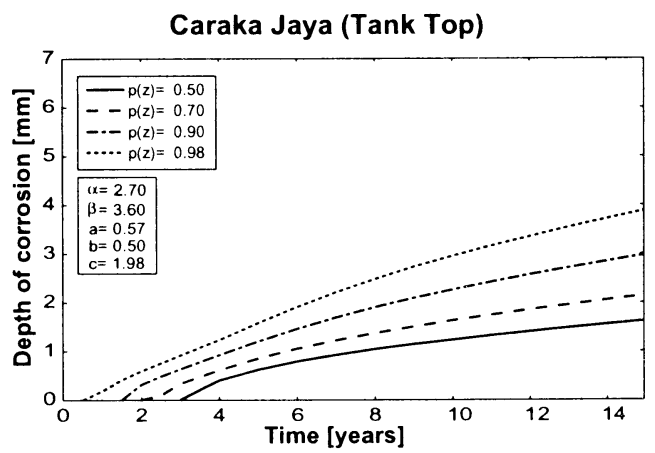

(b) On tank top 
Caraka Jaya (Bulk Head - Cargo Hold)

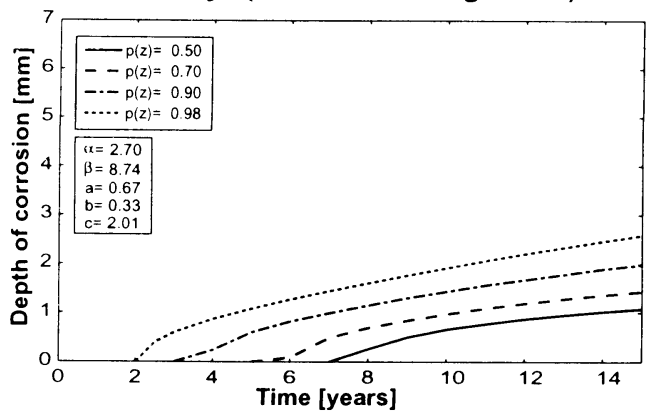

(c) On bulk head - cargo hold

Caraka Jaya (Bilge Plate)

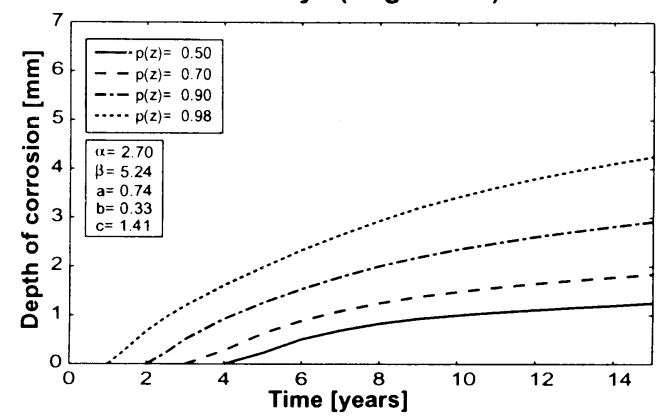

(e) On bilge Plate

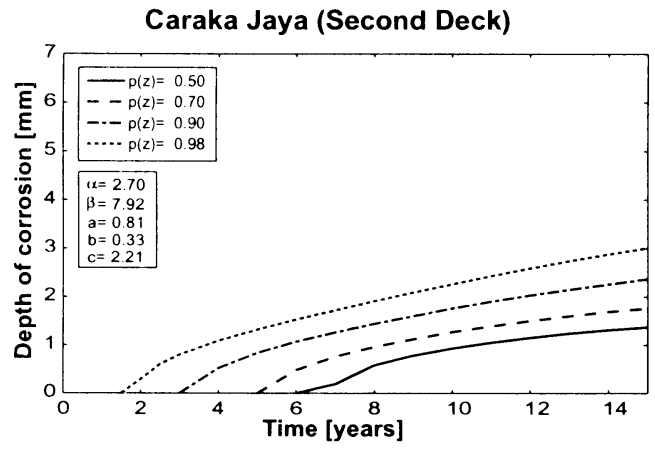

(g) On second deck

Fig. 3 Evaluated behaviour of corrosion

From the figure it is seen that the corrosion degradation is remarkable for main deck, and bottom plate members. The annual corrosion rate obtained by dividing the thickness diminution of an aged member by the ship's age was $0.155 \mathrm{~mm} /$ year for main deck, $0.087 \mathrm{~mm} /$ year for tank top, $0.045 \mathrm{~mm} /$ year for bulkhead(cargo hold), $0.104 \mathrm{~mm} /$ year for bottom plate, $0.082 \mathrm{~mm} /$ year for bilge plate, and $0.082 \mathrm{~mm} /$ year for side plate. The corrosion diminution curves at $P(Z)=0.5$ in Fig. 3 show good agreement with the annual corrosion

\section{Caraka Jaya (Bottom Plate)}

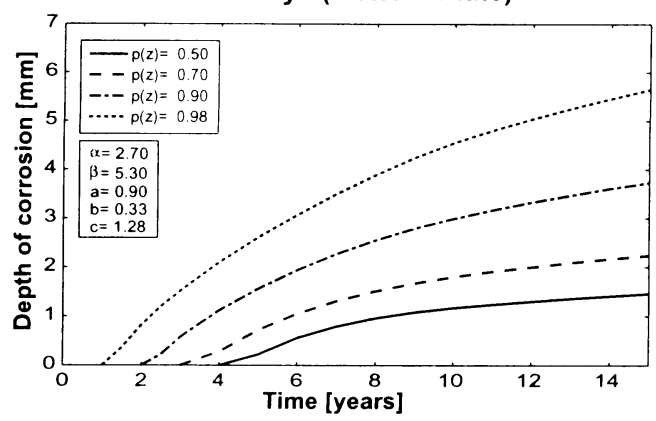

(d) On bottom plate

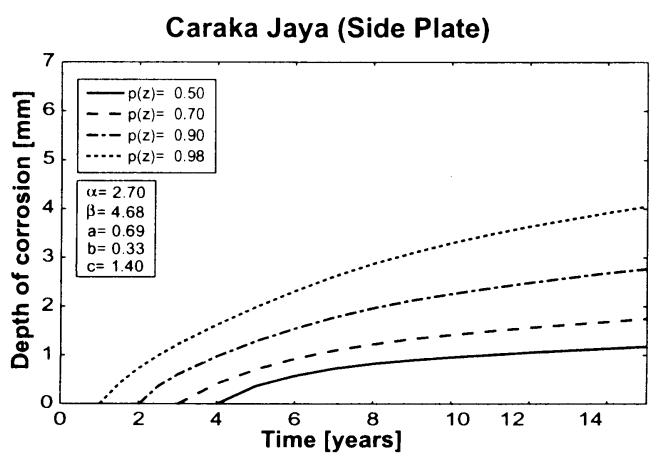

(f) On side plate

rates. From the figure, the distribution property of the corrosion depth $Z$ can be easily understood by comparing the corrosion diminution curves for respective $P(Z)$.

\subsection{Comparison of the proposed model with Yamamoto's model}

In order to investigate the effectiveness of the proposed method, the corrosion evaluation was carried out for Class NK Ships and the corrosion diminution evaluated by the proposed method was compared with that evaluated by Yamamoto's method.

The ships were bulk carriers having dead weight more than 100,000 ton. The plate thickness measurements were on the points of bulk head in ballast and cargo hold and lower stool in ballast and cargo hold. The measured data are listed in the paper by Yamamoto et al. ${ }^{1)}$. The proposed model was applied to those data.

In the proposed method, parameter $\alpha$ was set to 2.70, as in the analysis of Caraka Jaya ships. Parameter $b$ was adjusted to the same value as in Yamamoto's paper and the parameters $a$ and $c$ were optimised by using the above mentioned loglikelihood function. 


\section{Proposed method}

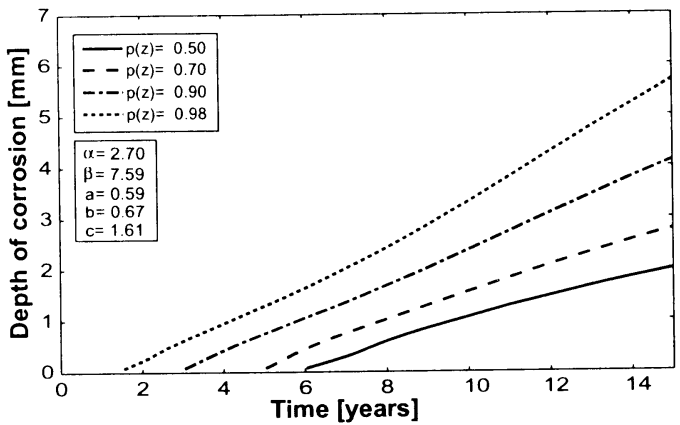

\section{Proposed method}

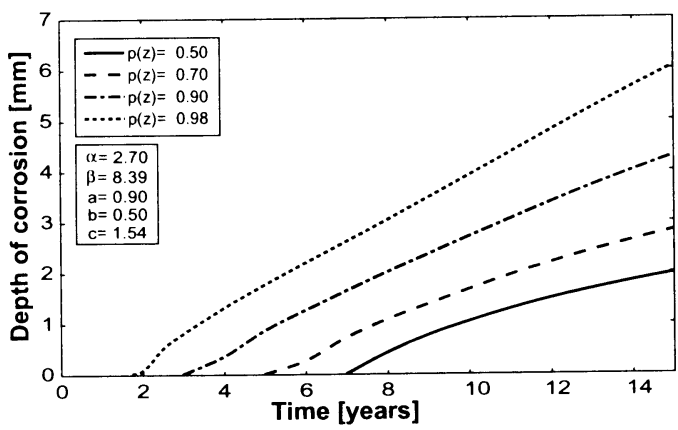

(b) NK bulk head - cargo hold

\section{Proposed method}

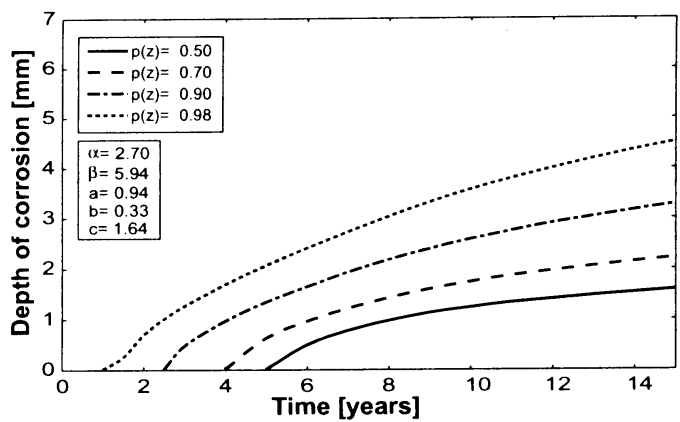

(c) NK lower stool - ballast hold

\section{Proposed method}

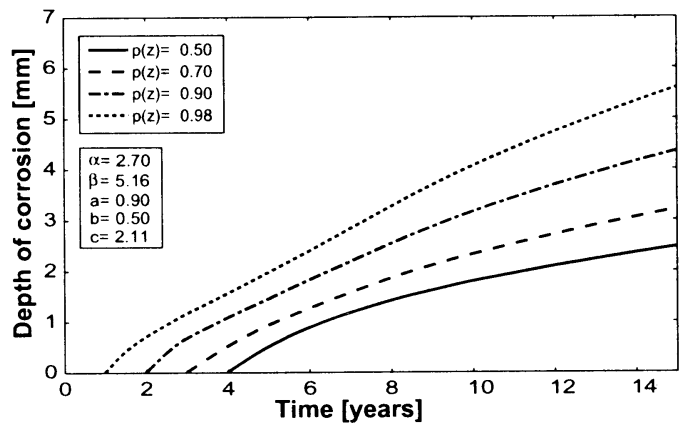

(a) NK bulk head - ballast hold

Yamamoto's method

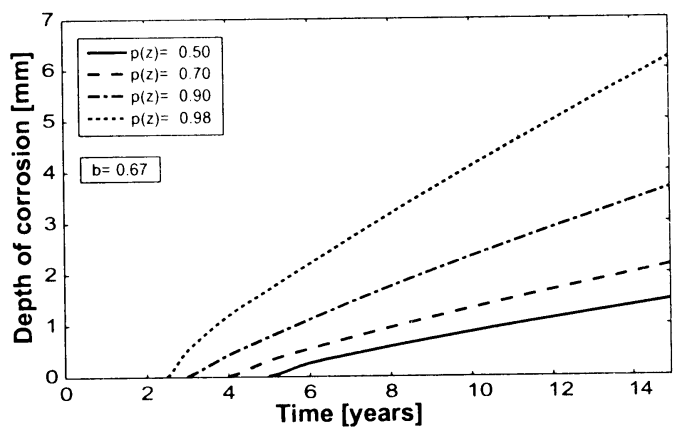

Yamamoto's method

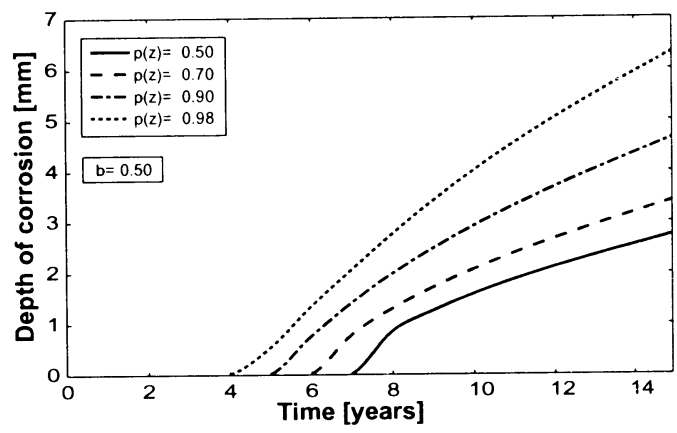

Yamamoto's method

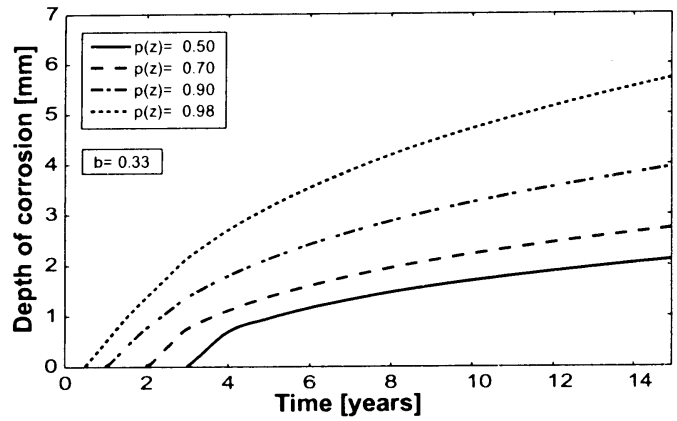

Yamamoto's method

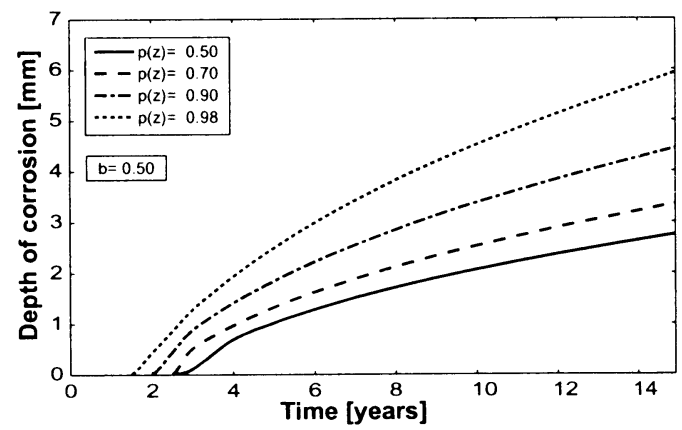

(d) NK lower stool - cargo hold

Fig. 4 Comparison of the proposed model with Yamamoto's model 
In Yamamoto's method, first, the ranges of possible corrosion depth $Z$ and ship's age $T$ were assumed. Then, $P(Z)$ was calculated by numerically integrating the equation (25) in his paper ${ }^{1)}$ for a lot of combination points $(Z, T)$ in the range. After that, the contour lines having the levels of $P(Z)=50,70,90$ and 98 percent were drawn respectively on the $Z-T$ coordinate.

Fig. 4 compares the $Z-T$ relationships calculated by the proposed method and Yamamoto's method for the four locations. From the figure it is seen that the corrosion diminutions by both methods show similar result. Therefore, the authors think that the proposed method can practically be used for the evaluation of corrosion progress of actual ships.

\section{Longitudinal Strength Degradation of Caraka Jaya Ships Due to Corrosion}

It is obvious that the plate thickness reduction of ship hull members due to corrosion influences the structural strength of the ship ${ }^{5)}$. In this chapter, the change of longitudinal strength of Caraka Jaya Ships due to corrosion is examined based on the probabilistic approach mentioned in the foregoing chapter.

Table 3: Dimensions of Caraka Jaya ships

\begin{tabular}{|c|c|c|c|c|c|c|}
\hline Building & DWT & \multicolumn{5}{|c|}{ Principal dimensions (m) } \\
\cline { 3 - 7 } phase & (ton) & $L_{O A}$ & $L_{p p}$ & $B$ & $D$ & $d$ \\
\hline I & 3,000 & 98 & 92 & 16.5 & 7.8 & 5 \\
II & 3,650 & 98 & 92.8 & 16.5 & 7.8 & 5.4 \\
\hline
\end{tabular}

Table 3 shows the overall dimensions of the Caraka Jaya ships. Fig. 5 shows the shape and dimensions at the midship section. The interesting values related with longitudinal strength may be as follows.

1. Change of the height of the centre of gravity: $h_{G}$

2. Change of the moment of inertia around $y y^{\prime}$ axis, where $y y^{\prime}$ is the height of the centre of gravity from the bottom: $I_{y}$

3. Stress increase or decrease on the deck member: $\sigma_{d} / \sigma_{d 0}$

4. Stress increase or decrease on the bottom member: $\sigma_{b} / \sigma_{b 0}$.
In the above, $\sigma_{d}$ and $\sigma_{b}$ are the stresses on the deck and bottom member at time T. $\sigma_{d 0}$ and $\sigma_{b 0}$ are the initial stresses at $T=0$.

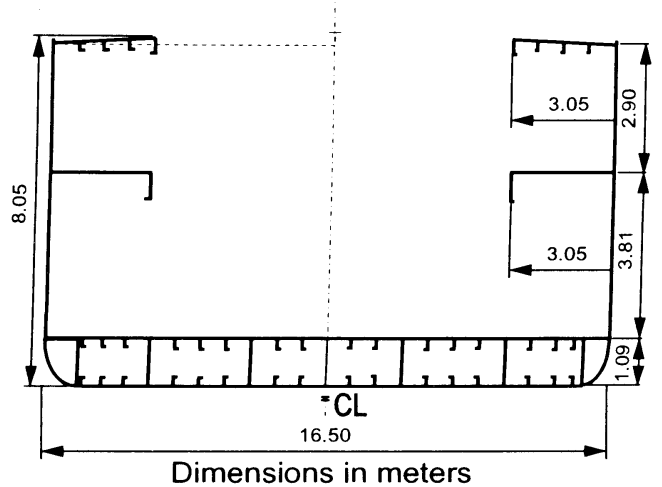

Fig. 5 Midship Section of Caraka Jaya ships

Corrosion data are available for the members of main deck, second deck, side plate, bilge plate, bottom plate and tank top plate. However, the corrosion data was not obtained for the girders and frames. So, the analysis was carried out for the following two cases.

In the first analysis (Analysis I), corrosion was not considered for the girder and frame members. In the second analysis (Analysis II), the corrosion of the girder and frame members was assumed the same as the adjacent members. That is the corrosion degradation of deck frame, bottom frame and tank top frames are the same as that of deck plate, bottom plate and tank top plate, respectively. The corrosion degradation of girder plates was assumed the same as that of bottom plate.

Fig. 6 shows the change of $h_{G}, I_{y}, \sigma_{d} / \sigma_{d 0}$ and $\sigma_{b} / \sigma_{b 0}$ with the service years until 25 years. The cumulative probability of corrosion depth $P(Z)$ is assumed as 50, 70 and 90 percent, respectively. This calculation was carried out assuming that all the members take the same $P(Z)$. This assumption is the worst condition. It is seen from the figure that the height of centre of gravity increases with time. Both the deck and bottom stresses increase according to the corrosion degradation. The corrosion of girder and frame members influences the longitudinal strength considerably. A plate renewal strategy to maintain the longitudinal strength may be planned using these calculations. 

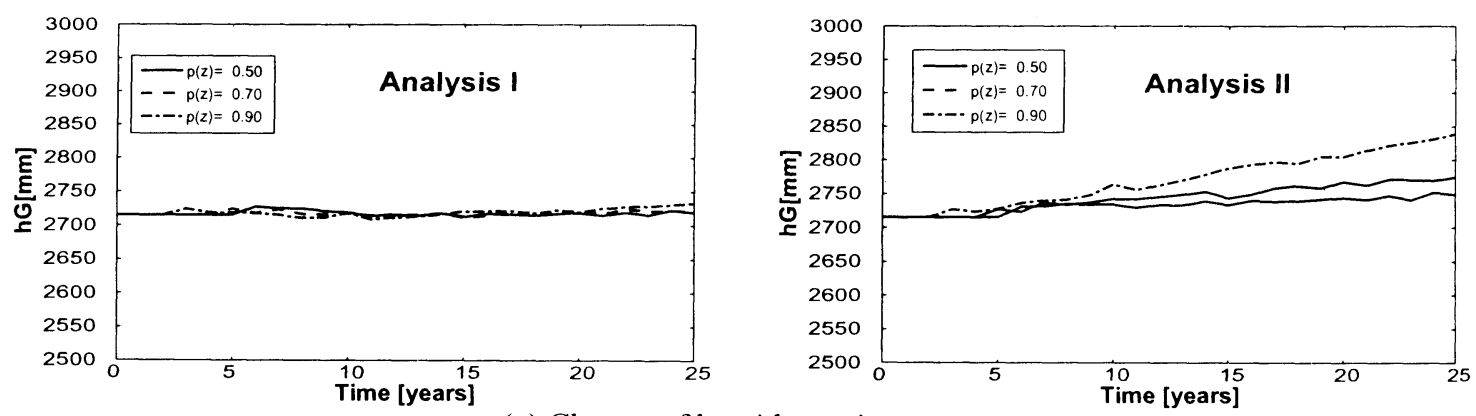

(a) Change of $h_{6}$ with service years
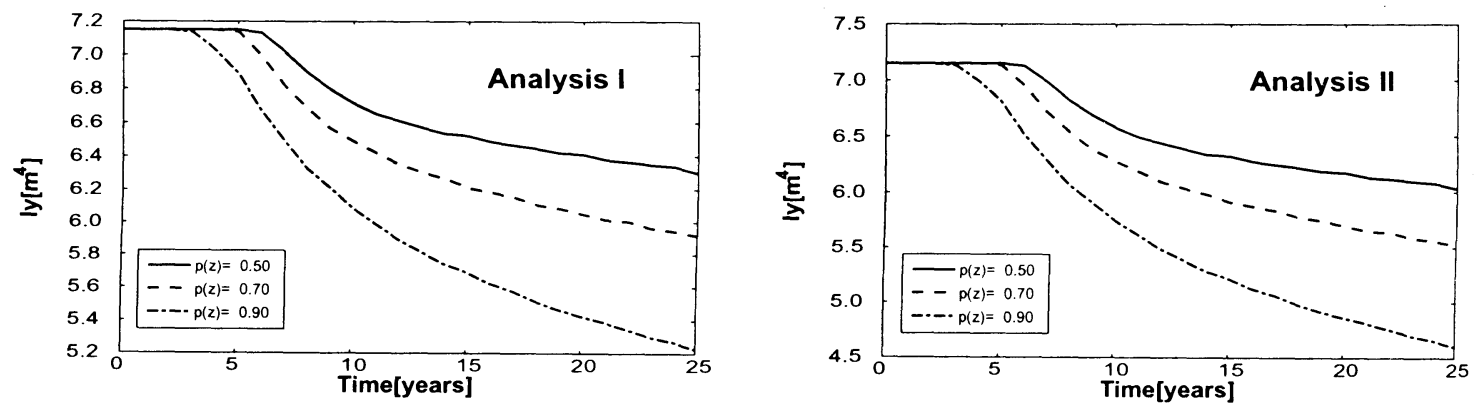

(b) Change of $I_{y}$ with service years
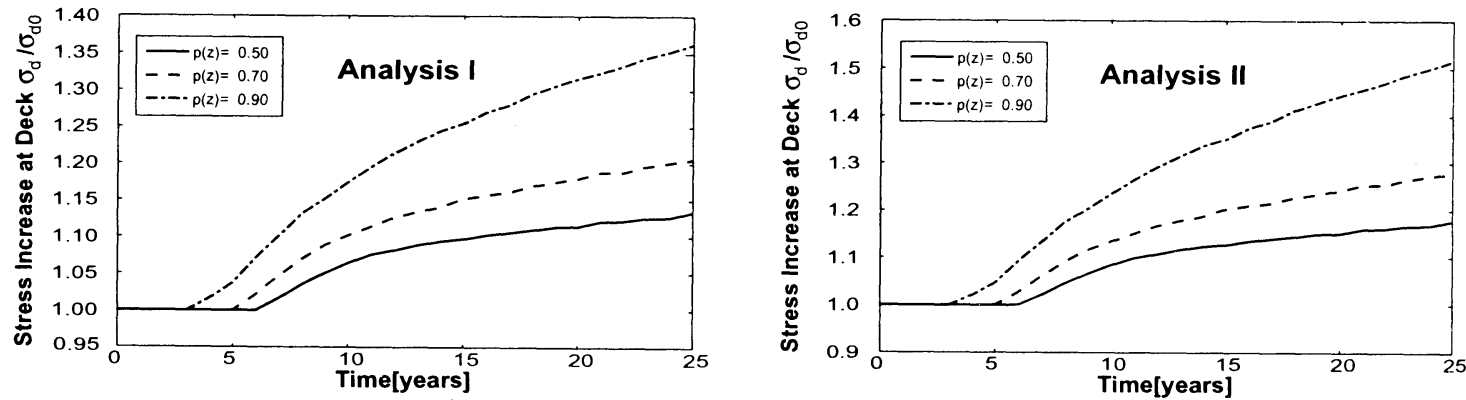

(c) Change of deck stress with service years
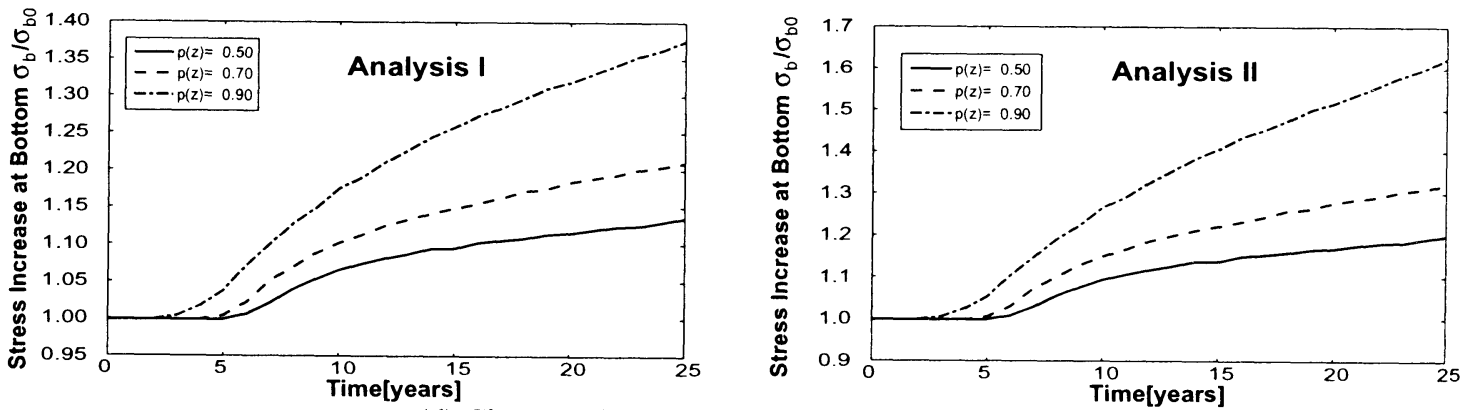

(d) Change of bottom stress with service years

Fig. 6 Change of longitudinal strength of Caraka Jaya ships 


\section{Conclusions}

In this paper, a simple probabilistic model was developed for the evaluation of the corrosion degradation of ship hull members. In the model, corrosion was assumed to be the result of two sequential processes: generation of pitting points and progress behaviour of pitting points after their generation. A closed form relationship between corrosion depth and ship's age considering the distribution property was obtained. The parameters of the model were determined based on empirical data of plate thickness measurements. The maximum likelihood method was employed for this purpose.

The applicability of the proposed model was examined for the corrosion data of Caraka Jaya ships. The difference between the proposed model and Yamamoto's model was discussed with corrosion data of Class NK ships. Because of the simplicity of the model, it was concluded that the proposed model is applicable at the corrosion evaluation of actual ships. Further, the effect of corrosion on the longitudinal strength degradation of Caraka Jaya ships was discussed.

\section{References}

1) N. Yamamoto and K. Ikegami: A Study on the Degradation of Coating and Corrosion of Ship's Hull Based on the Probabilistic Approach, Journal of Offshore Mechanics and Arctic Engineering, Vol.120, pp.121128,1998 .

2) Samudro, Y. Fujimoto and E. Shintaku: Study on Hull Corrosion Degradation of Caraka Jaya Ships Based on Field Data Analysis, Transaction of The West Japan Society of Naval Architects, No. 100, 2000, to be published.

3) Samudro, Y. Fujimoto: Welding Quality in Indonesian Medium Shipyards and the effective Elements to Improve the Quality, Transaction of The West Japan Society of Naval Architects, No. 98, 1999, pp. 231247.

4) M. Matoba, N. Yamamoto, T. Watanabe and M. Umino: Effect of Corrosion and its Protection on Hull Strength (1st report), Journal of the Society of the Naval Architects of Japan, Vol.175, pp.271-280, 1994.

5) C. Guades Soares and Y. Garbatov: Reliability of Maintained Ship Hulls Subjected to Corrosion, Journal of Ship Research, Vol.40, No.3, pp.235-243, 1996.

6) J.K. Paik, S.K. Kim, S.K. Lee and Y.E. Park: A Probabilistic Corrosion Rate Estimation Model for Longitudinal Strength Members of Bulk Carriers, Journal of Ship \& Ocean Technology, Vol.2, No.1, pp.5870,1998 . 